\title{
Assessment and predictors of physical functioning post-hospital discharge in survivors of critical illness
}

Kevin J. Solverson ${ }^{1}$, Christopher Grant ${ }^{1,2}$ and Christopher J. Doig ${ }^{1,3^{*}}$

\begin{abstract}
Background: Prior studies of physical functioning after critical illness have been mostly limited to survivors of acute respiratory distress syndrome. The purpose of this study was to objectively assess muscle strength and physical functioning in survivors of critical illness from a general ICU and the associations of these measures to health-related quality of life (HRQL), mental health and critical illness variables.

Methods: This was a prospective cohort study of 56 patients admitted to a medical ICU (length of stay $\geq 4$ days) from April 1, 2009, and March 31, 2010. Patients were assessed in clinic at 3 months post-hospital discharge. Muscle strength and physical functioning were measured using hand-held dynamometry and the 6-min walk test. HRQL was assessed using the short-form 36 (SF-36) and EuroQol-5D (EQ-5D) questionnaires.

Results: Three months post-hospital discharge, median age- and sex-matched muscle strength was reduced across all muscle groups. The median 6-min walk distance was $72 \%$ of predicted. Physical functioning was associated with reductions in self-reported HRQL (SF-36, EQ-5D) and increased anxiety. Univariate regression modeling showed that reduced muscle strength and 6-min walk distance were associated with sepsis but not ICU length of stay. Multivariate regression modeling showed that sepsis and corticosteroid use were associated with a reduced 6-min walk distance, but again ICU length of stay was not.

Conclusions: Survivors of critical illness have reduced strength in multiple muscle groups and impaired exercise tolerance impacting both HRQL and mental health. These outcomes were worsened by sepsis and corticosteroid use in the ICU but not ICU length of stay. Interventions to minimizing the burden of sepsis in critically ill patients may improve long-term outcomes.
\end{abstract}

Keywords: Critical care, Muscle weakness, Muscle strength dynamometer, Sepsis, Recovery of function, Adult

\section{Background}

As more patients are surviving critical illness, examining longer-term outcomes becomes increasingly important. There is increasing evidence that critical illness survivors have impaired physical functioning, increased prevalence of mental health disorders and reduced health-related quality of life (HRQL) [1-6].

\footnotetext{
*Correspondence: cdoig@ucalgary.ca

${ }^{1}$ Department of Critical Care Medicine, Cumming School of Medicine,

University of Calgary, 3134 Hospital Drive NW, Calgary, AB T2N 2T9,

Canada

Full list of author information is available at the end of the article
}

Critically ill patients have been shown to develop multifactorial weakness termed ICU-acquired weakness (ICUAW), and these patients are at risk of prolonged ICU lengths of stay, increased mechanical ventilation time, prolonged weakness and poor hospital outcomes [7-13]. Muscle biopsies taken during critical illness have shown wasting of the muscle fibers and increased catabolic metabolism [14-17]. Risk factors for ICUAW include prolonged immobility, mechanical ventilation, corticosteroid and neuromuscular blockade administration and cytokine-related injury from systemic inflammation $[5,7,9,10,17-24]$. However, the duration of physical 
impairment after hospital discharge secondary to critical illness and the predictors of severity remain unclear.

Studies that have objectively examined long-term physical function have primarily focused on survivors of acute respiratory distress syndrome (ARDS) and not the general ICU survivor population. Long-term physical function of ARDS survivors was first objectively described by Herridge et al. [5] landmark paper using the 6-min walk test $(6 \mathrm{MWT})$. Recent post-ICU studies have used manual muscle testing (MMT) for the assessment of muscle strength in addition to the 6MWT; however, MMT has limitations including a ceiling effect in less severe muscle weakness $[25,26]$. Isokinetic muscle strength testing using hand-held dynamometry has been shown to be a more sensitive and objective method of strength testing compared to MMT [25, 27-30]. However, to date handheld dynamometry has not been used in the ICU survivor population, despite its common use in other patient populations [31-34].

The goal of our study was to objectively examine muscle strength and physical functioning using hand-held dynamometry and the 6MWT in critical illness survivors 3 months after hospital discharge. Additionally, we sought to determine whether muscle strength or physical functioning was associated with HRQL, mental health or critical illness variables such as severity and type of illness and ICU length of stay.

\section{Methods}

\section{Design}

This was a prospective longitudinal cohort study of patients who were admitted to a 25-bed multidisciplinary tertiary referral ICU, which also served as the trauma center for southern Alberta [35]. Enrollment occurred between April 1, 2009, and March 31, 2010. At the time of study enrollment, there were two full-time equivalent physiotherapists; however, no patients were mobilized while intubated in the ICU. The initiation of physiotherapy was up to the discretion of the attending physician.

Patients assessed in the ICU follow-up clinic were adult patients ( $\geq 18$ years), admitted to the ICU with a minimum 4-day length of ICU stay. Patients were excluded if they had traumatic brain injuries, spinal cord injuries, pre-existing neurocognitive or neuromuscular disorders, acute strokes or lived outside of the immediate municipality of Calgary. Patients in the ICU were screened for eligibility during the initial $48 \mathrm{~h}$ and approached for follow-up once they had been admitted to the ICU for a minimum of 4 days. Due to limited capacity in the ICU follow-up clinic, patients were enrolled consecutively until clinical capacity was met at which point screening would be temporally suspended. Patients enrolled in the ICU were assessed at 3 months after hospital discharge.
A total of 61 patients met inclusion criteria, 4 patients declined follow-up, and 1 patient was lost to follow-up. Attendance at the clinic was presented as a natural continuation of care following hospitalization, which individuals had the option to refuse. We sought permission from these patients to include their clinical data in our study. This study was approved by the University of Calgary Human Research Ethics Board (ID\# E-22574), and written informed consent was obtained from all patients.

\section{Instruments/questionnaires}

A single trained individual (author KS) assessed peripheral muscle strength using hand-held dynamometry. The JAMAR (5030J1) hydraulic hand dynamometer and the Chatillon dynamometer (K-MSC-200) were used for all muscle strength assessments. All measurements were taken in kilograms to the nearest hundredth of a kilogram. Each muscle group (handgrip, triceps, biceps, ankle dorsiflexors, hamstrings and quadriceps) was measured according to previously validated protocols [36]. For each muscle group, patients were asked to exert a maximal effort for 3-4 s against the dynamometer, which was in a fixed position. Three measurements were collected for each muscle group, alternating between patient sides between measurements. For each muscle group, the highest force generated on the patient's dominant side was used for analysis. The National Isometric Muscle Strength Database Consortium [36] was used for age- and sex-standardized normative values. The 6MWT was used to assess overall physical functioning. Previously published guidelines and procedures were followed [37], and age and sex normative values were obtained from Enright et al. [38].

The assessment of HRQL was done using short-form 36 (SF-36) and EuroQol-5D (EQ-5D) surveys [39]. The SF-36 survey was reported as each domain ranging from 0 to 100 (higher scores indicate better HRQL), and the physical and mental composite scores (PCS, MCS) were standardized to Canadian population norms (score of 50 represents the average normative value) [40]. The Hospital Anxiety and Depression Scale (HADS) was used to assess anxiety and depression, scores ranging from 0 to 21 [41]. A score $>7$ on either the anxiety or depression section indicates severe symptoms. All questionnaires were administered at the time of the patient's clinical visit.

\section{Statistical analysis}

All clinical data were entered into a study-specific database. These data were merged with clinical and outcome data from an ICU-specific longitudinal database, details described elsewhere [42]. All data analysis was performed using Stata 11.0 (Stata Corp, College Station, 
TX). Descriptive statistics were used to report patient demographics, hand-held dynamometry testing and the 6MWT.

Multiple linear regression models were used to assess the association between the strength of each muscle group (independent variable), 6MWT, EQ-5D and the SF-36 (dependent variables). The EQ-5D domains were modeled as a dichotomous variable $(0=$ no problems, $1=$ reporting any problems). Multiple univariate and a single multivariate linear regression analysis assessed the association of the following ICU risk factors (dependent variables) to patient's predicted peripheral muscle strength or 6MWT (independent variables): (1) ICU length of stay (LOS), (2) hospital LOS, (3) severity of illness as measured by the mean Acute Physiology and Chronic Health Evaluation (APACHE) II score, (4) degree of organ failure measure by the Sequential Organ Failure Assessment (SOFA) score, (5) presence of sepsis (defined using the 2001 American College of Chest Physicians guideline [43]), (6) presence of ARDS (defined as a $\mathrm{PaO} 2: \mathrm{FiO} 2$ ratio of 200 or less while mechanically ventilated with evidence of airspace disease in all four quadrants on chest radiograph), (7) any corticosteroid use, (8) any neuromuscular blocker use (9), duration of ventilation and (10) Functional Comorbidity Index score. For the multivariate linear regression, all ICU risk factors were analyzed in the model and variables that had a $p$ value $<0.05$ were carried forward in the analysis to create the final model.

\section{Results}

During the study period, 56 patients were seen in the ICU follow-up clinic. The median (IQR) age was 61 years $(41,68)$, and $54 \%$ were males (Table 1$)$. Prior to ICU admission, $57 \%$ of patients had one or more pre-existing comorbidity and $100 \%$ were living independently at home. The median (IQR) first APACHE II score and maximum SOFA scores were $19(16,24)$ and $11(9,14)$, respectively. Only $18 \%$ of patients received corticosteroids, and $21 \%$ received neuromuscular blockers anytime while in the ICU. No patient with ARDS received corticosteroids. The median (IQR) days of mechanical ventilation and ICU and hospital LOS were 8 days (4, $11), 11$ days $(6,15)$ and 12 days $(8,12)$, respectively. The median (IQR) time to follow-up was 72 days $(54,92)$ after hospital discharge.

Patient's median dynamometry-measured muscle strength was reduced across all muscle groups when compared to age- and sex-matched data (Table 2). The median (IQR) percent-predicted strength of the handgrips $61 \%(25,108)$, quadriceps $59 \%(35,88)$ and the ankle dorsiflexors $62 \%(42,92)$ all showed the greatest impairment 3 months after critical illness. For all the
Table 1 Baseline patient characteristics

\begin{tabular}{|c|c|}
\hline Variable & All patients \\
\hline \multicolumn{2}{|l|}{ Baseline characteristics prior to admission } \\
\hline Age (year) & $61(41,68)$ \\
\hline Male [n (\%)] & $30(54)$ \\
\hline Pre-existing comorbidity [n (\%)] & $32(57)$ \\
\hline Charlson comorbidity index score & $3(1,4)$ \\
\hline Functional Comorbidity Index score & $1(0,2)$ \\
\hline Living independently at home [n (\%)] & $56(100)$ \\
\hline Body mass index $\left(\mathrm{kg} / \mathrm{m}^{2}\right)$ & $26(22,33)$ \\
\hline \multicolumn{2}{|l|}{ ICU characteristics } \\
\hline \multicolumn{2}{|l|}{ Diagnosis at ICU admission [n (\%)] } \\
\hline Respiratory failure & $37(66)$ \\
\hline Intra-abdominal infection & $7(13)$ \\
\hline Urologic infection & $3(5)$ \\
\hline Poly-trauma & $4(7)$ \\
\hline Other & $5(9)$ \\
\hline Sepsis present during admission [n (\%)] & $39(70)$ \\
\hline ARDS present during admission [n (\%)] & $13(23 \%)$ \\
\hline Any corticosteroid use [n (\%)] & $10(18)$ \\
\hline $\begin{array}{l}\text { Daily dose corticosteroids if received any, mg } \\
\text { (prednisone equivalent) }\end{array}$ & $57(35,82)$ \\
\hline Any neuromuscular blocker use [n (\%)] & $12(21)$ \\
\hline APACHE II score & $19(16,24)$ \\
\hline SOFA score maximum value & $11(9,14)$ \\
\hline Length of mechanical ventilation (day) & $8(4,11)$ \\
\hline Length of ICU stay (day) & $11(6,15)$ \\
\hline Length of hospital stay (day) & $12(8,21)$ \\
\hline Time to follow-up after hospital discharge (day) & $72(54,92)$ \\
\hline
\end{tabular}

ARDS acute respiratory distress syndrome, APACHE II Acute Physiology and Chronic Health Evaluation, SOFA Sequential Organ Failure Assessment, ICU intensive care unit

a Reported as median (interquartile range) unless specified

muscle groups, over $50 \%$ of the patients did not achieve $80 \%$ of their age- and sex-matched predicted strength. The median (IQR) distance walked in $6 \mathrm{~min}$ and percent predicted were $382 \mathrm{~m}(291,480)$ and $70 \%(53,88)$, respectively. In total, $55 \%$ of patients did not achieve at least $80 \%$ of their age- and sex-matched predicted $6 \mathrm{MWT}$ distance. The maximum strength results of each muscle group statistically correlated with the 6MWT distance.

Table 3 outlines individual regression analyses evaluating the associations of physical functioning to HRQL and mental health. Reporting problems in the domains mobility $(p=0.003)$, usual activities $(p=0.006)$, pain and discomfort $(\mathrm{p}=0.031)$ of the EQ-5D were each associated with reduced predicted $6 \mathrm{MWT}$ distance. Patient's overall impression of their global health using the EQ-5D VAS was also associated with performance on the 6MWT $(\mathrm{p}=0.025)$. Among the muscle groups strength tested, 
Table 2 Muscle strength and physical functioning of critical illness survivors at 3 months after hospital discharge measured using hand-held dynamometry and the 6-min walk test

\begin{tabular}{|c|c|c|c|c|}
\hline Variable $(n=56)$ & $\begin{array}{l}\text { Measurement (median, } \\
\text { IQR) }\end{array}$ & $\begin{array}{l}\% \text { predicted (median, } \\
\text { IQR) }\end{array}$ & $\begin{array}{l}\% \text { of patients }<80 \% \text { predicted } \\
\text { strength }\end{array}$ & $\begin{array}{l}\text { Correlation with the 6MWT } \\
\left(R^{2}, p \text { value }\right)\end{array}$ \\
\hline \multicolumn{5}{|c|}{ Maximum muscle strength $(\mathrm{kg})^{\mathrm{a}}$} \\
\hline Grip & $20.4(9.1,30.6)$ & $61 \%(25,108)$ & 60 & $0.28(<0.001)$ \\
\hline Triceps & $12.3(8.7,16.7)$ & $71 \%(45,126)$ & 52 & $0.31(<0.001)$ \\
\hline Biceps & $14.5(11.7,19.0)$ & $72 \%(45,126)$ & 52 & $0.28(<0.001)$ \\
\hline Hamstrings & $13.2(10.3,17.6)$ & $77 \%(47,114)$ & 53 & $0.30(<0.001)$ \\
\hline Quadriceps & $20.3(16.4,25.6)$ & $59 \%(35,88)$ & 69 & $0.14(0.013)$ \\
\hline Ankle dorsiflexors & $13.7(10.6,17.2)$ & $62 \%(42,92)$ & 57 & $0.13(<0.001)$ \\
\hline
\end{tabular}

6MWT 6-min walk test

a Strength results reported as the maximum force generated on the dominant body side

Table 3 Associations of physical functioning and health-related quality of life at 3 months after hospital discharge

\begin{tabular}{|c|c|c|c|c|c|c|c|}
\hline Variable $\mathrm{n}=50^{\mathrm{a}}$ & 6-Minute walk test & Grip & Triceps & Biceps & Hamstrings & Quadriceps & Ankle dorsiflexors \\
\hline \multicolumn{8}{|l|}{ EuroQol-5D } \\
\hline Mobility & $-0.211(0.003)$ & $-0.297(0.030)$ & $-0.223(0.144)$ & $-0.228(0.097)$ & $-0.283(0.021)$ & $-0.252(0.019)$ & $-0.140(0.125)$ \\
\hline Self-care & $-0.177(0.067)$ & $-0.132(0.435)$ & $-0.170(0.372)$ & $0.165(0.336)$ & $-0.198(0.190)$ & $-0.177(0.197)$ & $-0.142(0.212)$ \\
\hline Usual activities & $-0.177(0.006)$ & $-0.166(0.153)$ & $-0.044(0.736)$ & $-0.061(0.606)$ & $-0.103(0.335)$ & $-0.070(0.446)$ & $-0.127(0.105)$ \\
\hline Pain/discomfort & $-0.125(0.031)$ & $-0.020(0.855)$ & $-0.011(0.929)$ & $-0.105(0.345)$ & $-0.096(0.359)$ & $-0.072(0.412)$ & $-0.031(0.688)$ \\
\hline Anxiety/depression & $-0.123(0.079)$ & $-0.099(0.476)$ & $-0.120(0.421)$ & $-0.065(0.630)$ & $-0.021(0.866)$ & $-0.001(0.994)$ & $-0.007(0.941)$ \\
\hline Visual analog scale ${ }^{c}$ & $0.050(0.025)$ & $0.324(0.428)$ & $0.028(0.534)$ & $0.018(0.662)$ & $0.026(0.480)$ & $-0.010(0.759)$ & $-0.009(0.746)$ \\
\hline \multicolumn{8}{|l|}{ Short-from 36} \\
\hline Physical functioning $^{d}$ & $0.005(0.001)$ & $0.006(0.019)$ & $0.004(0.178)$ & $0.004(0.112)$ & $0.005(0.026)$ & $0.004(0.062)$ & $0.003(0.063)$ \\
\hline $\begin{array}{l}\text { Physical composite } \\
\text { score }^{\mathrm{e}}\end{array}$ & $0.010(0.001)$ & $0.008(0.185)$ & $0.000(0.997)$ & $0.007(0.266)$ & $0.009(0.105)$ & $0.008(0.113)$ & $0.004(0.320)$ \\
\hline $\begin{array}{l}\text { Mental composite } \\
\text { score }^{\mathrm{e}}\end{array}$ & $0.005(0.118)$ & $0.010(0.128)$ & $0.003(0.712)$ & $0.006(0.409)$ & $0.005(0.416)$ & $0.005(0.308)$ & $0.004(0.453)$ \\
\hline \multicolumn{8}{|l|}{$\operatorname{HADS}^{f}$} \\
\hline Anxiety & $-0.029(0.001)$ & $-0.023(0.176)$ & $-0.025(0.179)$ & $-0.025(0.130)$ & $-0.023(0.123)$ & $-0.018(0.16)$ & $-0.014(0.251)$ \\
\hline Depression & $-0.016(0.098)$ & $-0.033(0.080)$ & $-0.008(0.718)$ & $-0.023(0.214)$ & $-0.012(0.174)$ & $-0.027(0.067)$ & $0.010(0.450)$ \\
\hline
\end{tabular}

ICU intensive care unit, LOS length of stay, APACHE Acute Physiology and Chronic Health Evaluation, SOFA Sequential Organ Failure Assessment, 6MWT 6-min walk test

a $\beta$-Coefficients ( $p$ value) modeled as univariate regression analyses. $6 \mathrm{MWT}$ and muscle strength modeled as percent predicted. $\beta$-Coefficients represent the percent change in the physical functioning variable per unit change in exposure variable

b Each domain of the EuroQol-5D questionnaire modeled as 0 "no problems" and 1 "any problems"

c Visual analog scale of the EQ-5D scores ranges from 0 to 10 based on patients perspective of current overall health

d The physical function domain is standardized to a 0-100 scale, and higher scores indicate better health-related quality of life

e Physical and mental composite scores of the short-form 36 survey, standardized to Canadian norms. Scores can range from 0 to 100 and are standardized to 50 , which represents the average Canadian's health-related quality of life

f Hospital Anxiety and Depression Scale (HADS), scores range from 0 to 21, significant symptoms of anxiety/depression defined as scores $\geq 8$

grip $(\mathrm{p}=0.030)$, hamstring $(\mathrm{p}=0.021)$ and quadriceps $(\mathrm{p}=0.019)$ weakness were associated with increasing impairment on the mobility domain of the EQ-5D.

The physical function domain of the SF-36 was associated with the percent-predicted 6MWT distance $(\mathrm{p}<0.001)$, grip strength $(\mathrm{p}=0.019)$ and hamstring strength $(\mathrm{p}=0.026)$. The $6 \mathrm{MWT}$ percent-predicted distance was associated with the physical composite score of the SF-36 $(\mathrm{p}=0.003)$ and the anxiety score of the Hospital and Anxiety Depression Scale. Patient's percent-predicted $6 \mathrm{MWT}$ and muscle strength for all muscle groups, except triceps, were statistically associated with reported values in the general health domain (patient's perspective of overall health) of the SF-36. Additionally, patients predicted grip strength and 6MWT were associated with the vitality, social functioning and role emotional domains, with the 6MWT also associated with the physical role and emotional role domains (data not shown). 
Univariate regression analysis showed that ICU LOS $(p=0.002)$, number of days mechanically ventilated $(p=0.002)$, the presence of sepsis $(p=0.044)$ and corticosteroid use in the ICU $(p=0.019)$ were independently associated with patient's percent-predicted 6MWT distance (Table 4). Sepsis was the only ICU risk factor associated with a reduction in the $6 \mathrm{MWT}$ by an estimated $17 \%$ and reductions in strength of all muscle groups (except quadriceps). Muscle strength did not correlate with patient's ICU or hospital LOS. Both the 6MWT and peripheral muscle strength did not show an association with the Functional Comorbidity Index, APACHE II or SOFA scores. There were no associations found between neuromuscular medication use or the presence of ARDS in the ICU and the 6MWT, peripheral muscle strength or self-reported physical functioning (SF-36, EQ-5D) (data not shown).

The multivariate linear regression analysis assessing predictors of 6MWT distance included the ICU risk factors that were statistically significant in the univariate regression, with the exception of mechanical ventilation duration as it is highly correlated with ICU LOS. The presence of sepsis $(\beta=-0.159, \mathrm{p}=0.030)$ and any corticosteroid use $(\beta=-0.188, p=0.037)$ in the ICU were associated with patient's age- and sex-matched 6MWT distance $\left(\mathrm{R}^{2}=0.24\right)$, and ICU LOS $(\beta=-0.002$, $\mathrm{p}=0.233)$ was no longer statistically significant. Additionally, total cumulative steroid dose and average daily corticosteroid dose were analyzed in regression model and there was no association with physical function or muscle strength (data not shown).

\section{Discussion}

This is the first study to report the use of hand-held dynamometry assessment of multiple muscle groups in the general ICU survivor population. We demonstrated that approximately 3 months after hospital discharge the majority of ICU survivors experienced persistent muscle weakness across all muscle groups. The quadriceps were the weakest muscle group measured, with the median percent-predicted strength achieved at $59 \%$. Fan et al. [23] described grip strength in ARDS survivors, in keeping with our results, reporting a range of 50-70 \% percent-predicted strength 3-12 months after ICU discharge. Global muscle weakness in ARDS survivors, measured using MMT, has a reported prevalence between 8 and $22 \%$ during the first year after discharge $[23,24]$. However, we found that over $50 \%$ of patients did not achieve $80 \%$ of their age- and sex-matched predicted hand-held dynamometry-measured muscle strength. These differences may be due to the limited sensitivity of MMT to detect less severe weakness [24], or that our study included all ICU patients versus only ARDS patients.

A reduction in percent-predicted 6MWT distance and grip strength was associated with a decrease in the physical functioning domain on the SF-36 survey, similar to results found in prior studies [22-24]. We found that poor 6MWT performance was also associated with reduced HRQL in nearly all of the domains of the EQ-5D and SF-36, including the physical composite score, suggesting there is a strong link between patients overall physical functioning and HRQL. Further supporting this finding, the muscle strength of patient's was independently associated with the patient's perception of their mobility and general health on the SF-36. Poor 6MWT performance was associated with increased symptoms of anxiety, showing the connection between physical functioning and mental health [6]. It is important to note there was an expected association between muscle strength and the 6MWT; however, the 6MWT was

Table 4 Summary of predictors of muscle strength and physical functioning at 3 months after hospital discharge

\begin{tabular}{|c|c|c|c|c|c|c|c|}
\hline Variable $n=50^{a}$ & 6-Minute walk test & Grip & Triceps & Biceps & Hamstrings & Quadriceps & Ankle dorsiflexors \\
\hline$U$ LOS, days & -0.0 & $-0.002(0.85)$ & $0.010(0.305)$ & $-0.005(0.537)$ & $-0.001(0.806)$ & $0.000(0.922)$ & $-0.001(0.685)$ \\
\hline Hospital LOS, days & $-0.003(0.079)$ & $-0.001(0.965)$ & $0.002(0.727)$ & $0.003(0.498)$ & $0.000(0.969)$ & $0.003(0.274)$ & $0.001(0.755)$ \\
\hline $\begin{array}{l}\text { Mechanical ventilation, } \\
\text { days }\end{array}$ & & $-0.001(0.905)$ & $-0.009(0.378)$ & & & $0.001(0.809)$ & \\
\hline resence of sepsis & -0. & 09) & 45) & 33) & -0.3 & -0 & -0 \\
\hline APACHE II score & -0.00 & $-0.002(0.868)$ & $-0.008(0.515)$ & $0.003(0.802)$ & $0.003(0.755)$ & $0.011(0.212)$ & .397) \\
\hline SOFA score & & $0.022(0.229)$ & $0.021(0.325)$ & $0.027(0.167)$ & $0.020(0.219)$ & $0.019(0.174)$ & 0.017 \\
\hline $\begin{array}{l}\text { Functional Comorbidity } \\
\text { Index }\end{array}$ & -0.019 (0.593) & $-0.070(0.247)$ & $-0.111(0.114)$ & $-0.050(0.437)$ & $-0.000(0.998)$ & $0.013(0.803)$ & $-0.044(0.274)$ \\
\hline Any corticosteroid use ${ }^{b}$ & $-0.215(0.019)$ & $-0.304(0.092)$ & $-0.382(0.062)$ & $-0.359(0.052)$ & $-0.320(0.047)$ & $-0.222(0.137)$ & $-0.221(0.058)$ \\
\hline
\end{tabular}

ICU intensive care unit, LOS length of stay, APACHE Acute Physiology and Chronic Health Evaluation, SOFA Sequential Organ Failure Assessment, 6MWT 6-min walk test ${ }^{a} \beta$-Coefficients ( $p$ value) modeled as univariate regression analyses. 6 MWT and muscle strength modeled as percent predicted. $\beta$-Coefficients represent the percent change in the physical functioning variable per unit change in exposure variable

b Also analyzed using cumulative ICU and average daily corticosteroid dose with no significance found 
associated with more domains of HRQL than muscle strength alone. This finding highlights that the $6 \mathrm{MWT}$ accounts for more than just physical functioning or muscle strength, and is a composite assessment that may also be influenced by cardiopulmonary status, mental health, motivation, neurological status and bodily pain [24, 44, 45].

ICU LOS is thought to be a surrogate marker for immobility [23]. This is a well-described risk factor for muscle wasting and weakness in both healthy controls and patients in ICU $[10,46]$. However, in our multivariate regression analysis ICU LOS was not found to be a predictor of muscle strength or 6MWT. The model included both corticosteroid use and the presence of sepsis, suggesting that ICU LOS, an indicator of immobility, may be confounded or collinearly correlated by these variables. Therefore, interventions to reduce immobility in the ICU may not decrease the prevalence of long-term impaired muscle strength or physical functioning. However, the benefits of interventions such as early mobilization still need to be examined in long-term randomized controlled trials using the appropriate physical outcome measures [47-50].

The presence of sepsis during critical illness was significantly associated with both impaired physical functioning and muscle weakness in nearly all muscle groups (the most of any ICU risk factor) as part of the univariate and multivariate linear regression analysis. Systemic inflammation and cytokine release have been shown to induce muscle injury and increase the incidence of ICUAW detected in the ICU $[7,51-53]$. Our findings support a premise that inflammation during critical illness can result in long-term detectable impairment of muscle function [3]. Our study suggests sepsis, as a mechanism possibly related to the acute systemic inflammatory process, may be more important than ICU LOS or immobility in long-term physical impairment.

Our analysis showed that any exposure to corticosteroid use during critical illness was associated with reduced physical functioning. This supports the findings of prior studies in ARDS survivors and recommendations to avoid corticosteroid use in the ICU in order to lessen the degree of patient's long-term functional disability [5, $10,24]$. We did not see any effect on physical functioning when analyzing average daily corticosteroid dose or cumulative dose, similar to other studies [10]. Prior studies examining the effects of corticosteroids were limited to patients who had ARDS, but surprisingly none of our patients who had ARDS (23 \%) received any corticosteroids. This highlights the variability of clinical practice across institutions and the importance of studying longterm physical functioning outcomes across the general ICU population.
The limitations of this study include that it is a singlecenter study with a relatively small sample size. Additionally, patient recruitment was limited due to the small capacity of the follow-up clinic. Patients who may have met inclusion criteria were not screened, potentially creating selection bias. However, patient selection was random and we had a relatively few number of patients decline enrollment or who were lost to follow-up.

\section{Conclusion}

We found that in survivors of critical illness approximately 3 months after hospital discharge patients had significant impairment in muscle strength and physical functioning measured using hand-held dynamometry and the 6MWT. Patients with impaired physical functioning and muscle weakness were found to have reduced HRQL. Sepsis and corticosteroid use were found to be an important risk factor for reduced long-term physical function, whereas ICU length of stay (a surrogate for immobility) was not.

\section{Abbreviations \\ ARDS: acute respiratory distress syndrome; APACHE II: Acute Physiology and Chronic Health Evaluation II; ESS: Epworth Sleepiness Scale; EQ-5D: EuroQol- 5D; HADS: Hospital Anxiety and Depression Scale; ICU: intensive care unit; ICUAW: intensive care unit-acquired weakness; IQR: interquartile range; LOS: length of stay; MCS: mental composite summary; MMT: manual muscle test- ing; PCS: physical composite summary; PQSI: Pittsburgh Sleep Quality Index; PSG: polysomnography; SF-36: short-form 36; SOFA: Sequential Organ Failure Assessment; 6MWT: 6-min walk test.}

\section{Authors' contributions}

KS designed the study, performed data collection and analyses and wrote the manuscript. CG interpreted the data and edited the manuscript. CD designed the study, performed data collection and analyses and edited the manuscript. All authors read and approved the final manuscript.

\section{Author details}

${ }^{1}$ Department of Critical Care Medicine, Cumming School of Medicine, University of Calgary, 3134 Hospital Drive NW, Calgary, AB T2N 2T9, Canada. ${ }^{2}$ Division of Physical Medicine and Rehabilitation, Cumming School of Medicine, University of Calgary, 3134 Hospital Drive NW, Calgary, AB T2N 2T9, Canada. ${ }^{3}$ Department of Community Health Sciences, Cumming School of Medicine, University of Calgary, 3134 Hospital Drive NW, Calgary, AB T2N 2T9, Canada.

\section{Funding}

This work was funded as part of a grant from Alberta Innovates Health Solutions

\section{Competing interests}

The authors declare that they have no competing interests.

Received: 9 March 2016 Accepted: 25 August 2016

Published online: 20 September 2016

\section{References}

1. Dowdy DW, Eid MP, Dennison CR, Mendez-Tellez PA, Herridge MS, Guallar $E$, et al. Quality of life after acute respiratory distress syndrome: a metaanalysis. Intensive Care Med. 2006;32(8):1115-24. 
2. Barnato $A E$, Albert $S M$, Angus DC, Lave JR, Degenholtz HB. Disability among elderly survivors of mechanical ventilation. Am J Respir Crit Care Med. 2011;183(8):1037-42.

3. Iwashyna TJ, Ely EW, Smith DM, Langa KM. Long-term cognitive impairment and functional disability among survivors of severe sepsis. JAMA. 2010;304(16):1787-94.

4. Jackson JC, Mitchell N, Hopkins RO. Cognitive functioning, mental health, and quality of life in ICU survivors: an overview. Crit Care Clin. 2009;25(3):615-28.

5. Herridge MS, Cheung AM, Tansey CM, Matte-Martyn A, Diaz-Granados N, Al-Saidi F, et al. One-year outcomes in survivors of the acute respiratory distress syndrome. N Engl J Med. 2003;348(8):683-93.

6. Bienvenu OJ, Colantuoni E, Mendez-Tellez PA, Dinglas VD, Shanholtz C, Husain N, et al. Depressive symptoms and impaired physical function after acute lung injury: a 2-year longitudinal study. Am J Respir Crit Care Med. 2012;185(5):517-24

7. De Jonghe B, Lacherade JC, Durand MC, Sharshar T. Critical illness neuromuscular syndromes. Crit Care Clin. 2007:23(1):55-69.

8. Ginz HF, laizzo PA, Girard T, Urwyler A, Pargger H. Decreased isometric skeletal muscle force in critically ill patients. Swiss Med Wkly. 2005;135(37-38):555-61.

9. Stevens RD, Dowdy DW, Michaels RK, Mendez-Tellez PA, Pronovost PJ, Needham DM. Neuromuscular dysfunction acquired in critical illness: a systematic review. Intensive Care Med. 2007;33(11):1876-91.

10. De Jonghe B, Sharshar T, Lefaucheur JP, Authier FJ, Durand-Zaleski I, Boussarsar $\mathrm{M}$, et al. Paresis acquired in the intensive care unit: a prospective multicenter study. JAMA. 2002;288(22):2859-67.

11. Bierbrauer J, Koch S, Olbricht C, Hamati J, Lodka D, Schneider J, et al. Early type II fiber atrophy in intensive care unit patients with nonexcitable muscle membrane. Crit Care Med. 2012;40(2):647-50.

12. Ali NA, O'Brien JM Jr, Hoffmann SP, Phillips G, Garland A, Finley JC, et al. Acquired weakness, handgrip strength, and mortality in critically ill patients. Am J Respir Crit Care Med. 2008:178(3):261-8.

13. Hough CL, Steinberg KP, Thompson BT, Rubenfeld GD, Hudson LD. Intensive care unit-acquired neuromyopathy and corticosteroids in survivors of persistent ARDS. Intensive Care Med. 2009;35(1):63-8.

14. Levine S, Nguyen T, Taylor N, Friscia ME, Budak MT, Rothenberg P, et al. Rapid disuse atrophy of diaphragm fibers in mechanically ventilated humans. N Engl J Med. 2008;358(13):1327-35.

15. Wollersheim T, Woehlecke J, Krebs M, Hamati J, Lodka D, LutherSchroeder A, et al. Dynamics of myosin degradation in intensive care unit-acquired weakness during severe critical illness. Intensive Care Med. 2014;40(4):528-38.

16. Hermans G, Casaer MP, Clerckx B, Guiza F, Vanhullebusch T, Derde S, et al. Effect of tolerating macronutrient deficit on the development of intensive-care unit acquired weakness: a subanalysis of the EPaNIC trial. Lancet Respir Med. 2013;1 (8):621-9.

17. Puthucheary ZA, Rawal J, McPhail M, Connolly B, Ratnayake G, Chan $P$, et al. Acute skeletal muscle wasting in critical illness. JAMA. 2013;310(15):1591-600.

18. Schefold JC, Bierbrauer J, Weber-Carstens S. Intensive care unit-acquired weakness (ICUAW) and muscle wasting in critically ill patients with severe sepsis and septic shock. J Cachex Sarcopenia Muscle. 2010;1 (2):147-57.

19. Herridge MS, Batt J, Hopkins RO. The pathophysiology of long-term neuromuscular and cognitive outcomes following critical illness. Crit Care Clin. 2008;24(1):179-99.

20. van der Schaaf M, Dettling DS, Beelen A, Lucas C, Dongelmans DA, Nollet F. Poor functional status immediately after discharge from an intensive care unit. Disabil Rehabil. 2008:30(23):1812-8.

21. Semmler A, Okulla T, Kaiser M, Seifert B, Heneka MT. Long-term neuromuscular sequelae of critical illness. J Neurol. 2013;260(1):151-7.

22. Herridge MS, Tansey CM, Matte A, Tomlinson G, Diaz-Granados N, Cooper $A$, et al. Functional disability 5 years after acute respiratory distress syndrome. N Engl J Med. 2011:364(14):1293-304.

23. Fan E, Dowdy DW, Colantuoni E, Mendez-Tellez PA, Sevransky JE, Shanholtz C, et al. Physical complications in acute lung injury survivors: a twoyear longitudinal prospective study. Crit Care Med. 2014;42(4):849-59.

24. Needham DM, Wozniak AW, Hough CL, Morris PE, Dinglas VD, Jackson JC, et al. Risk factors for physical impairment after acute lung injury in a national, multicenter study. Am J Respir Crit Care Med. 2014;189(10):1214-24.
25. Bohannon RW. Manual muscle testing: does it meet the standards of an adequate screening test? Clin Rehabil. 2005;19(6):662-7.

26. Bohannon RW. Quantitative testing of muscle strength: issues and practical options for the geriatric population. Top Geriatr Rehabil. 2002;18(2):1-17.

27. Noreau L, Vachon J. Comparison of three methods to assess muscular strength in individuals with spinal cord injury. Spinal Cord. 1998;36(10):716-23.

28. Elliott D, Denehy L, Berney S, Alison JA. Assessing physical function and activity for survivors of a critical illness: a review of instruments. Aust Crit Care. 2011:24(3):155-66.

29. Visser J, Mans E, de Visser M, van den Berg-Vos RM, Franssen H, de Jong $J M$, et al. Comparison of maximal voluntary isometric contraction and hand-held dynamometry in measuring muscle strength of patients with progressive lower motor neuron syndrome. Neuromuscul Disord. 2003:13(9):744-50.

30. van der Ploeg RJ, Oosterhuis HJ, Reuvekamp J. Measuring muscle strength. J Neurol. 1984:231(4):200-3.

31. Robles PG, Mathur S, Janaudis-Fereira T, Dolmage TE, Goldstein RS, Brooks D. Measurement of peripheral muscle strength in individuals with chronic obstructive pulmonary disease: a systematic review. J Cardiopulm Rehabil Prev. 2011:31(1):11-24.

32. Baldwin CE, Paratz JD, Bersten AD. Muscle strength assessment in critically ill patients with handheld dynamometry: an investigation of reliability, minimal detectable change, and time to peak force generation. J Crit Care. 2013;28(1):77-86.

33. Vanpee G, Hermans G, Segers J, Gosselink R. Assessment of limb muscle strength in critically ill patients: a systematic review. Crit Care Med. 2014:42(3):701-11.

34. Vanpee G, Segers J, Van Mechelen H, Wouters P, Van den Berghe G, Hermans $G$, et al. The interobserver agreement of handheld dynamometry for muscle strength assessment in critically ill patients. Crit Care Med. 2011:39(8):1929-34

35. Laupland KB, Zygun DA, Davies HD, Church DL, Louie TJ, Doig CJ. Population-based assessment of intensive care unit-acquired bloodstream infections in adults: Incidence, risk factors, and associated mortality rate. Crit Care Med. 2002;30(11):2462-7.

36. The National Isometric Muscle Strength (NIMS) Database Consortium. Muscular weakness assessment: use of normal isometric strength data. Arch Phys Med Rehabil. 1996;77(12):1251-5.

37. ATS Committee on Proficiency Standards for Clinical Pulmonary Function Laboratories. ATS statement: guidelines for the six-minute walk test. Am J Respir Crit Care Med. 2002;166(1):111-7.

38. Enright PL, Sherrill DL Reference equations for the six-minute walk in healthy adults. Am J Respir Crit Care Med. 1998;158(5 Pt 1):1384-7.

39. Hayes JA, Black NA, Jenkinson C, Young JD, Rowan KM, Daly K, et al. Outcome measures for adult critical care: a systematic review. Health Technol Assess. 2000:4(24):1-111.

40. Hopman WM, Towheed T, Anastassiades T, Tenenhouse A, Poliquin S, Berger C, Canadian Multicentre Osteoporosis Study Research Group, et al. Canadian normative data for the SF-36 health survey. CMAJ. 2000;163(3):265-71

41. Zigmond AS, Snaith RP. The hospital anxiety and depression scale. Acta Psychiatr Scand. 1983;67(6):361-70.

42. Doig CJ, Zygun DA, Fick GH, Laupland KB, Boiteau PJ, Shahpori R, et al. Study of clinical course of organ dysfunction in intensive care. Crit Care Med. 2004;32(2):384-90.

43. Levy MM, Fink MP, Marshall JC, Abraham E, Angus D, Cook D, et al. 2001 SCCM/ESICM/ACCP/ATS/SIS international sepsis definitions conference. Crit Care Med. 2003;31(4):1250-6.

44. Benington S, McWilliams D, Eddleston J, Atkinson D. Exercise testing in survivors of intensive care-is there a role for cardiopulmonary exercise testing? J Crit Care. 2012;27(1):89-94.

45. Solway S, Brooks D, Lacasse Y, Thomas S. A qualitative systematic overview of the measurement properties of functional walk tests used in the cardiorespiratory domain. Chest. 2001:119(1):256-70.

46. Brower RG. Consequences of bed rest. Crit Care Med. 2009;37(10 Suppl):S422-8.

47. Morris PE, Goad A, Thompson C, Taylor K, Harry B, Passmore L, et al. Early intensive care unit mobility therapy in the treatment of acute respiratory failure. Crit Care Med. 2008;36(8):2238-43. 
48. Schweickert WD, Pohlman MC, PohIman AS, Nigos C, Pawlik AJ, Esbrook $\mathrm{CL}$, et al. Early physical and occupational therapy in mechanically ventilated, critically ill patients: a randomised controlled trial. Lancet. 2009;373(9678):1874-82.

49. Kayambu G, Boots RJ, Paratz JD. Early rehabilitation in sepsis: a prospective randomised controlled trial investigating functional and physiological outcomes: the i-PERFORM Trial (Protocol Article). BMC Anesthesiol. 2011;11:21.

50. Hermans G, De Jonghe B, Bruyninckx F, Van den Berghe G. Interventions for preventing critical illness polyneuropathy and critical illness myopathy. Cochrane Database Syst Rev. 2009;1:006832.
51. Baracos V, Rodemann HP, Dinarello CA, Goldberg AL. Stimulation of muscle protein degradation and prostaglandin E2 release by leukocytic pyrogen (interleukin-1). A mechanism for the increased degradation of muscle proteins during fever. N Engl J Med. 1983;308(10):553-8.

52. Wagenmakers AJ. Muscle function in critically ill patients. Clin Nutr. 2001;20(5):451-4.

53. Klaude M, Mori M, Tjader I, Gustafsson T, Wernerman J, Rooyackers O. Protein metabolism and gene expression in skeletal muscle of critically ill patients with sepsis. Clin Sci. 2012;122(3):133-42.

\section{Submit your manuscript to a SpringerOpen ${ }^{\circ}$ journal and benefit from:}

- Convenient online submission

\section{- Rigorous peer review}

Immediate publication on acceptance

- Open access: articles freely available online

- High visibility within the field

- Retaining the copyright to your article 